\title{
Risk factors for hysterectomy among patients with placenta previa totalis
}

\author{
Korkut Daglar, ${ }^{1}$ Aytekin Tokmak, ${ }^{1}$ Ayse Kirbas, ${ }^{1}$ Ozgur Kara, ${ }^{1}$ Hakan Timur, ${ }^{1}$ Dilek \\ Uygur $^{1}$
}

Key Words: Placenta previa, placenta accreta, peripartum hysterectomy, Cesarean section

\begin{abstract}
Objective: The aim of the study is to assess risk factors for hysterectomy among patients with placenta previa totalis (PPT).

Methods: The medical records of all patients delivered by cesarean section (CS) for PPT were retrospectively reviewed. Eligible cases were divided into those who underwent peripartum hysterectomy $(\mathrm{PH})$ and those who did not. The two groups were compared in terms of demographics, operative features and perinatal outcomes. Logistic regression analysis was used to identify risk factors associated with hysterectomy.
\end{abstract}

Results: $P H$ was performed in 43 (44.7\%) patients with PPT. Referral patients were older when compared with those without hysterectomy (p: 0.029). The median values for gravidity, parity, number of live children and previous CS were statistically significantly higher in the hysterectomy group $(p<0.05)$. Perioperative need for blood transfusion, anteriorly placed placenta and abnormal placental invasion were statistically significantly more frequent in the hysterectomy group $(p<0.001)$. Intraoperative complication rate was higher in this group, and bladder injury was the most common complication. No significant differences were observed between the groups in terms of perinatal outcomes. In binomial logistic regression analysis; advanced maternal age $(\geq$ 31 years), number of previous CS ( $\geq 2)$, preoperative need for blood transfusion, and abnormal placental invasion were found to be independent risk factors for $\mathrm{PH}$ in patients with PPT.

Conclusion: The findings of this study suggest that placenta invasion anomaly, advanced maternal age, increased number of previous CS, and increased need for blood transfusion are important risk factors for $\mathrm{PH}$ in patients with PPT.

${ }^{1}$ Zekai Tahir Burak Women's Health Research and Education Hospital, Department of Obstetrics and Gynecology, Division of Perinatology, Ankara, Turkey

\section{Introduction}

Placenta previa (PP) is defined as the implantation of placental tissue

Please cite this paper as: Daglar K, Tokmak A, Kirbas A, Kara O, Timur H, Uygur D Risk factors for hysterectomy among patients with placenta previa totalis. Proc Obstet Gynecol. 2016;6(2): Article 3 [ 10 p.]. Available from: http://ir.uiowa.edu/pog/ Free full text article.

Corresponding author: Aytekin Tokmak, M.D. Zekai Tahir Burak Women's Health Education and Research Hospital, Talatpaşa Bulvarı, Hamamönü, Altındağ, 06230 Ankara, Turkey. Telephone: +90 5056335064 . Fax: +90 31230659 17. aytekintokmak@gmail.com

Financial Disclosure: The authors report no conflict of interest.

Received 16 June 2016; accepted 17 August 2016

Copyright: (c) 2016 Daglar et al. This is an open-access article distributed under the terms of the Creative Commons Attribution License, which permits unrestricted use, distribution, and reproduction in any medium, provided the original author and source are credited. 
somewhere in the lower segment, either over or very close to the internal cervical os. The reported incidence for PP varies between 3 and 4 per 1000 deliveries. ${ }^{1}$ It is one of the most common causes of antepartum bleeding and is associated with an increased need for blood transfusions and preterm delivery. Maternal and perinatal morbidity and mortality is significantly higher in pregnant women with PP. ${ }^{2,3}$ The main problem that can occur during cesarean section (CS) of these patients is severe bleeding that may result in hysterectomy.

Several studies have identified similar risk factors for PP. The reported risk factors for PP are smoking, cocaine use, advanced maternal age, prior CS, recurrent abortions, male fetuses, and infertility treatment. ${ }^{4}$ However, studies identifying the risk factors regarding peripartum hysterectomy $(\mathrm{PH})$ in women with PP are relatively limited. The number of abortions as well as prior CS and placenta previa totalis (PPT) were found to be risk factors for hysterectomy in women with PP. ${ }^{5}$ Moreover, hysterectomy was significantly higher in patients with placenta accrete ${ }^{6}$ and anterior located PP. ${ }^{7}$ In this context, herein we aimed to define risk factors for hysterectomy in cases of PPT.

\section{Materials and Methods}

We analyzed retrospectively 104 cases of PPT treated at the Zekai Tahir Burak Women's Health Research and Education Hospital which is a tertiary referral hospital with total annual births of approximately 20,000 in Ankara, Turkey. The study protocol was performed accordingly to the principles of the Declaration of Helsinki and was carried out between January 2014 and July 2015 . The study was specifically approved by the Institutional Review Board. A written informed consent was given by each participant for their clinical records to be used in this study. Of all women 43 underwent $\mathrm{PH}$ and 61 did not. The data of the cases were collected from hospital records and patients' files. The two groups were compared for maternal demographic characteristics, peripartum events, and perinatal outcomes. The clinical characteristics evaluated were age, BMI, past medical and obstetric history, smoking status, placental location, urgency of delivery and gestational week at birth, birth weight, Apgar scores, neonatal intensive care unit (NICU) admission, perinatal mortality, preoperative and postoperative hemoglobin concentrations, preoperative and postoperative need for blood transfusion, and intraoperative complications. Histopathology results for patients undergoing $\mathrm{PH}$ were also recorded.

All women underwent CS due to PPT. The diagnosis of PPT was made by a perinatologist on generally accepted diagnostic criteria (the placental edge overlaps the internal os) based on a transvaginal ultrasound in the last trimester of pregnancy. A Voluson 730 Expert scanner (GE Medical systems, Kretztechnik $\mathrm{GmbH}$ \& OHG, Zipf, Austria) equipped with $5.0-9.0 \mathrm{MHz}$ transvaginal probe was used for ultrasonographic evaluation of the placenta. The clinical diagnosis of placenta accreta was made if manual removal of the placenta was partially or totally impossible and no cleavage plane 
exists between part or the entire placenta and the uterus. The definite diagnosis of placenta accreta was confirmed by histopathological examination of the specimen in women who underwent hysterectomy.

This is a high risk pregnancy unit having an experienced team. Perinatology residency training is given under the supervision of 4 clinical chiefs expert in high risk pregnancy, each with at least 20 years of experience. Perinatology assistants are obstetricians who completed 5 years of obstetrics and gynecology residencies with at least 2 years of expert experience. All PPT cases were included into this study regardless of the preoperative diagnosis of placental invasion abnormality. Hysterectomy decision following CS was made by at least two experienced clinical chiefs when standard medical (volume resuscitation, uterotonic drugs, Bakri balloon) and surgical (endouterine hemostatic or transuterine compression sutures, surgical uterine devascularization) treatment failure occurred for controlling postpartum hemorrhage due to morbidly adherent placenta and/or uterine atony. ${ }^{8}$ Transcatheter embolization had not been applied in any of the patients because no interventional radiology unit is present in our hospital. Moreover, hysterectomy without further attempts was performed in some patients with severe form of placenta accreta.

Routine preoperative tests were performed in patients during the admission, vital findings and anthropometric measurements were recorded. Maternal complete blood count parameters were also taken before operation and at least 6 hours after cesarean delivery. Body mass index (BMI) was calculated as weight (kg)/ height2 (m2) using a professional calibrated device at the admission for delivery. Gestational weeks were calculated according to last menstrual periods or were noted according to ultrasound screenings carried out on the first trimester in those who did not know their last menstrual period. Each patient was evaluated by ultrasonography and external fetal monitoring using cardiotocography. Patients were managed with bed rest and limited physical activity if remote from term and tocolysis was performed in those with significant uterine contractions. Antenatal betamethasone was administered to pregnant women at gestational week $\leq 34$ and having the risk of preterm delivery for fetal lung maturation. All cases were also evaluated in terms of surgical methods applied to control bleeding. The need for neonatal intensive care unit (NICU) was approved by a neonatologist for some cases due to respiratory distress, low birth weight $(<2500 \mathrm{~g})$, and intrauterine growth restriction (estimated fetal weight $<10 \%)$.

\section{Statistical analysis}

Statistical Package for the Social Sciences version 17.0 (SPSS Inc., Chicago, IL, USA) was used for statistical analysis. Means and standard deviations for quantitative data and numbers and percents for qualitative data were computed. KolmogorovSmirnov and Shapiro-Wilk tests were used to assess normal distribution of the univariate variables. Non parametric methods were used to analyze the 
variables which did not have a normal distribution. Chi-Square or Fisher's exact tests were used for categorical variables, where applicable. Independent-samples t test was used to compare unadjusted means between groups. Non parametric variables between groups were compared through Mann-Whitney $U$ test. The optimal cutoff points for numerical data which discriminate groups from each other were evaluated by receiver operating characteristic (ROC) analysis calculating area under the curve (AUC) as giving the maximum Youden index. Binomial logistic regression analysis was used to identify independent risk factors for $\mathrm{PH}$. The results were considered statistically significant when $p$ values were $<0.05$.

\section{Results}

During the 1.5-year period of the study, a total of 28,212 deliveries occurred in our hospital. It was found that 104 of these pregnancies were complicated with PPT. PH was performed in 43 (44.7\%) patients with PPT. The demographics features and clinical findings of the patients are shown in the Table

Table 1. The demographics features and clinical findings of the patients.

\begin{tabular}{lccc}
\hline & $\begin{array}{c}\text { Hysterectomy group } \\
\text { (n:43) }\end{array}$ & $\begin{array}{c}\text { Conservative group } \\
\text { (n:61) }\end{array}$ & P \\
\hline Age (years) & $33.0 \pm 3.9$ & $31.1 \pm 4.7$ & $\mathbf{0 . 0 2 9}$ \\
\hline BMI (kg/m2) & $28.7 \pm 3.8$ & $27.9 \pm 3.5$ & 0.262 \\
Gravidity & $3(2-9)$ & $3(1-8)$ & $\mathbf{0 . 0 1 4}$ \\
\hline Parity & $2(1-4)$ & $1(0-5)$ & $\mathbf{0 . 0 0 1}$ \\
\hline D\&C & $0(0-5)$ & $0(0-4)$ & 0.073 \\
\hline Abortion & $0(0-5)$ & $0(0-5)$ & 0.387 \\
\hline Alive & $2(0-4)$ & $1(0-5)$ & $\mathbf{0 . 0 0 2}$ \\
\hline Previous C-section & $2(0-3)$ & $0(0-4)$ & $\mathbf{0 . 0 0 0}$ \\
Gestational week at birth & $36(24-38)$ & $37(27-39)$ & $\mathbf{0 . 0 0 5}$ \\
\hline Birth weight (gr) & $2730(470-3410)$ & $2870(680-4500)$ & $\mathbf{0 . 0 3 8}$ \\
Apgar 5 & $9(0-9)$ & $9(5-9)$ & 0.651 \\
Preoperative Hb (g/dL) & $11.5 \pm 1.4$ & $11.6 \pm 1.1$ & 0.640 \\
Preoperative Hct (\%) & $34.2 \pm 4.2$ & $34.7 \pm 2.9$ & 0.411 \\
\hline Postoperative Hb (g/dL) & $9.9 \pm 1.4$ & $10.3 \pm 1.1$ & 0.077 \\
\hline Postoperative Hct (\%) & $29.9 \pm 4.2$ & $31.0 \pm 3.3$ & $\mathbf{0 . 0 0 6}$ \\
\hline Lowest detected Hb (g/dL) & $8.2 \pm 1.5$ & $9.7 \pm 2.1$ & 0.262 \\
Bakri inflation volume (cc) & & $186.2 \pm 64.9$ & \\
\hline
\end{tabular}

BMI; body mass index, D\&C; dilatation and curettage, Hb; hemoglobin, Hct;hematocrit. Data presented as mean \pm standard deviation and median(minimum-maximum). $P<0.05$ is considered as statistically significant.

The mean age of the patients was $33.0 \pm 3.9$ vs. $31.1 \pm 4.7$ years in the groups with and without hysterectomy, respectively ( $p$ : 0.029). The two groups were similar regarding mean BMI. The median values for gravidity, parity, number of live children and previous CS were statistically significantly higher in 
the hysterectomy group (all $\mathrm{p}<0.05$ ). Perioperative need for blood transfusion was also significantly higher in the hysterectomy group $(p<0.001)$. Patients who underwent hysterectomy gave birth earlier, and accordingly median birth weights of their newborns were significantly lower than those without hysterectomy $(p<0.05)$. One patient had previously undergone septum resection in the conservative treatment group. One patient in each group became pregnant following in-vitro fertilization treatment. Nifedipine as a tocolytic agent was used in three patients in both groups (p: 0.686).

Table 2. Distribution of the categorical variables between the two groups

\begin{tabular}{lccc}
\hline & $\begin{array}{c}\text { Hysterectomy group } \\
\text { (n:43) }\end{array}$ & $\begin{array}{c}\text { Conservative group } \\
\text { (n:61) }\end{array}$ & P \\
\hline Age $\geq \mathbf{3 1}$ & $36(83.7)$ & $32(52.5)$ & $\mathbf{0 . 0 0 1}$ \\
\hline BMI $\geq \mathbf{2 8 . 5}$ & $26(60.5)$ & $24(39.5)$ & $\mathbf{0 . 0 3 4}$ \\
Gravidity $\geq \mathbf{3}$ & $37(86)$ & $36(59)$ & $\mathbf{0 . 0 0 3}$ \\
\hline Parity $\geq \mathbf{2}$ & $31(72.1)$ & $25(41)$ & $\mathbf{0 . 0 0 2}$ \\
\hline Alive $\geq \mathbf{2}$ & $28(65.1)$ & $23(37.7)$ & $\mathbf{0 . 0 0 6}$ \\
\hline Previous C-section $\geq \mathbf{2}$ & $25(58.1)$ & $11(18)$ & $\mathbf{0 . 0 0 0}$ \\
\hline Smoker & $5(11.6)$ & $5(8.2)$ & 0.562 \\
\hline GW at birth $\leq \mathbf{3 6}$ & $31(72.1)$ & $27(44.3)$ & $\mathbf{0 . 0 0 5}$ \\
Male gender & $20(46.5)$ & $32(52.5)$ & 0.550 \\
\hline IUGR & $3(7)$ & $4(6.6)$ & 1.000 \\
Complication & $6(14)$ & 0 & $\mathbf{0 . 0 0 4}$ \\
NICU & $10(23.3)$ & $11(18)$ & 0.513 \\
\hline Perinatal mortality & $1(2.3)$ & $3(4.9)$ & 0.641 \\
\hline Placenta location & & & $\mathbf{0 . 0 0 0}$ \\
$\quad$ Anterior & $34(79.1)$ & $17(27.9)$ & \\
\hline Posterior & $9(20.9)$ & $44(71.1)$ & $\mathbf{0 . 0 0 0}$ \\
\hline Postop tx & $42(97.7)$ & $22(36.1)$ & $\mathbf{0 . 0 0 0}$ \\
\hline Urgency & $28(65.1)$ & $12(19.7)$ & 0.404 \\
\hline Abnormal Placental invasion & $7(16.3)$ & $14(23)$ & $\mathbf{0 . 0 0 0}$ \\
\hline BM; & $40(93)$ & $10(16.4)$ & \\
\hline
\end{tabular}

BMI; body mass index, GW; gestational week, IUGR; intrauterine growth restriction, NICU; neonatal intensive care unit, Tx; transfusion. Data are presented as $n(\%) . P<0.05$ is considered statistically significant

The percentage of smokers was similar in the two groups. No significant differences were observed between the groups in terms of perinatal morbidity and mortality. Anterior located placenta and abnormal placental invasion were statistically significantly more frequent in the hysterectomy group. Intraoperative complication rate was higher in this group, and bladder injury was the most 
common complication. Planned or emergent CS deliveries were not different in comparisons between the two groups. The cut-off value of age, BMI, gravidity, parity, number of live children and previous CS was found by using ROC curve analysis, and categorical distribution of recorded data was shown in Table 2.
In multivariate binomial logistic regression analysis; advanced maternal age ( $\geq 31$ years), number of previous CS ( $\geq 2$ ), preoperative need for blood transfusion, and abnormal placental invasion were found to be independent risk factors for $\mathrm{PH}$ in patients with PPT (Table 3).

Table 3. Logistic regression model for risk factors of peripartum hysterectomy in case of PP totalis

\begin{tabular}{|l|l|l|l|l|l|l|}
\hline Outcome: hysterectomy & \multicolumn{1}{|c|}{$\beta$} & S.E. & Wald & $\mathbf{P}$ & OR & 95\% CI \\
\hline Age $\geq \mathbf{3 1}$ & 3.851 & 1.297 & 8.809 & $\mathbf{0 . 0 0 3}$ & 47.035 & $3.698-598.165$ \\
\hline No. of previous C-section $\geq \mathbf{2}$ & 3.357 & 1.406 & 5.700 & $\mathbf{0 . 0 1 7}$ & 28.692 & $1.824-451.293$ \\
\hline No. of live children $\geq \mathbf{2}$ & 2.704 & 1.486 & 3.311 & 0.069 & 14.942 & $0.812-275.007$ \\
\hline Anterior located placenta(+) & 1.808 & 1.000 & 3.267 & 0.071 & 6.101 & $0.859-43.349$ \\
\hline Preop blood transfusion(+) & 3.203 & 1.576 & 4.131 & $\mathbf{0 . 0 4 2}$ & 24.618 & $1.121-540.552$ \\
\hline Abnormal Placental invasion (+) & 4.730 & 1.325 & 12.739 & $\mathbf{0 . 0 0 0}$ & 113.333 & $8.438-1522.235$ \\
\hline
\end{tabular}

SE; standard error, OR; odds ratio, Cl; confidence interval. $P<0.05$ is considered statistically significant

\section{Discussion}

Placenta previa is classically graded into three types depending on how close the lower edge of the placenta is to the internal os. If the placental edge totally covers the internal os, the placenta is called as PPT. It is one of the most feared pregnancy complications because of the increased risk of massive hemorrhage. The need for hysterectomy is significantly increased in PP cases with approximately 30\% relative risk. ${ }^{9}$ A recent study suggested that a combined ultrasound and clinical scoring model may predict peripartum complication in patients with PP. However, there is a need for more comprehensive and extensive studies for its routine use. ${ }^{10}$ In the present study we aimed to evaluate the risk factors for hysterectomy in patients with PPT. According to this study, placenta accreta, advanced maternal age, increased number of previous CS, and an increased need for blood transfusion were found to be risk factors for $\mathrm{PH}$.

Postpartum hysterectomy is performed when there is a life threatening hemorrhage which cannot be controlled by medical treatment during or after vaginal or cesarean delivery. Although its higher morbidity rates, it can be lifesaving when performed in emergent cases with appropriate indications. PP and accreta are important risk factors for $\mathrm{PH}$. To our knowledge, there are limited 
studies evaluating risk factors for $\mathrm{PH}$ in women with PP in the literature..$^{5,9,11,12}$ In those studies, previous abortion, previous CS, PPT, placenta accreta and gestational age at delivery were found to be risk factors for $\mathrm{PH}$. Unlike these studies, our study is the first which evaluates risk factors for hysterectomy in patients with PPT.

Placenta accreta refers to an abnormally invasive placental implantation depending on the defect in the decidua basalis. It constitutes approximately $80 \%$ of all cases of abnormal placentation, and complicates nearly $20 \%$ of pregnancies with PP. ${ }^{13,14}$ The incidence of abnormal placentation has steadily increased over the years. This marked increase has been attributed to the increasing prevalence of cesarean delivery in recent years. A study has reported that PP was as high as one in 533 deliveries. ${ }^{14}$ In our study, the incidence of placenta accreta seems to be higher than reported. This may be related to the inclusion of PPT solely into the study.

The incidence of emergency PH did not change significantly in the past decade. However, the indications and intraoperative interventions have changed significantly over the years. Previously uterine atony was the most frequently reported indication for $\mathrm{PH}^{15}$ In recent years, abnormal placentation has become more frequently pronounced due to the increasing cesarean delivery rates. ${ }^{16} \mathrm{~A}$ previous study conducted in our institution showed similar results. ${ }^{17}$ Similar to that study, Çetin et al. found that the most common indication for emergency $\mathrm{PH}$ was placental insertion abnormalities in their retrospective study of 18 cases. ${ }^{18}$ In the study of Owolabi et al., it was found that primary and repeat cesarean deliveries, advanced maternal age, obesity, and grand multiparity had a direct association with $\mathrm{PH}^{19}$ Uterine atony, PP/accreta, and severe obstetric hemorrhage were also found to be associated with hysterectomy. Miller et al. found that advanced maternal age and previous cesarean delivery were independent risk factors for placenta accreta among women with PP. ${ }^{13}$ Likewise; we confirmed that advanced maternal age is an independent risk factor for hysterectomy in patients with PPT.

Vaginal bleeding in PP, which is mostly observed during the last months of the pregnancy, is thought to result from the maturation of the lower uterine segment. As those areas where the placenta stings to decidua gradually thin to prepare for birth, placental separation causing bleeding occurs. Meanwhile the lower uterine segment is not be able to contract as needed to stop the bleeding. ${ }^{20}$ It may also cause separation of the placenta during manual vaginal examination and intercourse. PP, diagnosed with acute onset of approximately $80 \%$ of patients at around 34 weeks of pregnancy, is seen as painless bright red bleeding. ${ }^{21}$ There is no correlation observed between the number of bleeding episodes, degree of PP and fetal survival. ${ }^{22}$ In this study, we found that the amount of bleeding was higher in patients undergoing hysterectomy. Preoperative transfusion was an independent risk factor for hysterectomy.

Jang et al. found that anterior PP is 
associated with increased risk for $\mathrm{PH}$ in their study. ${ }^{7}$ In accordance with this study, anterior PP was more common among the hysterectomy group when compared with the conservative group. However, anterior PP lost its significance in the logistic regression analysis.

Our hospital is located in the middle region of Turkey, Ankara. This is a referral maternity hospital where the majority of its patients are usually referred from other local centers as an emergency. Consequently, the proportion of complicated cases referred to us is higher than normal. Although the present study covers a shorter period than the others, the number of patients included is larger. Some of these patients were in regular follow-up whereas the others who apply in an emergency were diagnosed preoperatively. Therefore, we were not able to determine the gestational age at initial diagnosis in all patients. As is evident from the findings, the higher prevalence of elective CS in the hysterectomy group could mean that the preoperative diagnosis of placenta accreta in which a planned delivery at 34th week of gestation is recommended $^{23}$ was more frequent in this group. This explains the higher rate of preterm birth in the hysterectomy group. The higher prevalence of placenta accreta in the hysterectomy group may be seen as a selection bias. However, we included all cases diagnosed with PPT into this study during the study period.

Ultrasound and magnetic resonance imaging are useful diagnostic tools in the preoperative diagnosis of placenta accreta. The main reasons for not considering the ultrasonographic diagnosis of adherent placenta in our study were that transvaginal ultrasonography was performed by different obstetricians, and preoperative diagnosis was not possible in all patients. Therefore, we also included all PPT patients regardless of the presence of a suspected diagnosis of placental accreta on antenatal visits. In addition, it should be considered that different decisions are often made under equivalent situations depending on individual surgeons.

In conclusion, the findings from this study suggest that placenta invasion anomaly, advanced maternal age, increased number of previous CS and need for preoperative blood transfusion may predict $\mathrm{PH}$ in women with PPT. Patients with these risk factors should be evaluated more carefully, and they should be delivered in a tertiary hospital with appropriate preparation for surgery. These patients should be informed in terms of hysterectomy. This approach will contribute to reducing maternal morbidity and mortality in this group of patients.

\section{References}

1. Faiz AS, Ananth CV. Etiology and risk factors for placenta previa: an overview and meta-analysis of observational studies. J Matern Fetal Neonatal Med. 2003 Mar;13(3):175-90. http://dx.doi.org/10.1080/imf.13.3.175.19 o PubMed PMID: 12820840. 
2. McShane PM, Heyl PS, Epstein MF. Maternal and perinatal morbidity resulting from placenta previa. Obstet Gynecol. $1985 \quad$ Feb;65(2):176-82. http://dx.doi.org/10.1097/00006254198509000-00008 PubMed PMID: 4038547.

3. Ananth CV, Smulian JC, Vintzileos AM. The effect of placenta previa on neonatal mortality: a population-based study in the United States, 1989 through 1997. Am J Obstet Gynecol. 2003 May;188(5):1299-304.

http://dx.doi.org/10.1067/mob.2003.76

PubMed PMID: 12748502.

4. Rosenberg $T$, Pariente $G$, Sergienko R, Wiznitzer A, Sheiner E. Critical analysis of risk factors and outcome of placenta previa. Arch Gynecol Obstet. 2011 Jul;284(1):47-51.

http://dx.doi.org/10.1007/s00404-0101598-7 Epub 2010 Jul 22. PubMed PMID: 20652281.

5. Choi SJ, Song SE, Jung KL, Oh SY, Kim JH, Roh CR. Antepartum risk factors associated with peripartum cesarean hysterectomy in women with placenta previa. Am J Perinatol. 2008 Jan;25(1):37-41.

http://dx.doi.org/10.1055/s-20071004834 Epub 2007 Dec 19. PubMed PMID: 18095214.

6. Zaki ZM, Bahar AM, Ali ME, Albar HA, Gerais MA. Risk factors and morbidity in patients with placenta previa accreta compared to placenta previa nonaccreta. Acta Obstet Gynecol Scand. 1998 Apr;77(4):391-4. http://dx.doi.org/10.1080/j.16000412.1998.00015.x PubMed PMID: 9598946.
7. Jang DG, We JS, Shin JU, Choi YJ, Ko HS, Park IY, Shin JC. Maternal outcomes according to placental position in placental previa. Int $\mathrm{J}$ Med Sci. 2011;8(5):439-44. http://dx.doi.org/10.7150/ijms.8.439 Epub 2011 Jul 23. PubMed PMID: 21814478; PubMed Central PMCID: PMC3149424.

8. WHO guidelines for the management of postpartum haemorrhage and retained placenta. [Internet] Geneva: World Health Organization, 2009. Available from:

http://whqlibdoc.who.int/publications/200 9/9789241598514 eng.pdf Accessed 10 August 2016.

9. Crane JM, Van den Hof MC, Dodds L, Armson BA, Liston R. Maternal complications with placenta previa. Am J Perinatol. 2000;17(2):101-5. http://dx.doi.org/10.1055/s-2000-9269 PubMed PMID: 11023169.

10. Yoon SY, You JY, Choi SJ, Oh SY, Kim $\mathrm{JH}$, Roh CR. A combined ultrasound and clinical scoring model for the prediction of peripartum complications in pregnancies complicated by placenta previa. Eur J Obstet Gynecol Reprod Biol. $2014 \quad$ Sep;180:111-5. http://dx.doi.org/10.1016/i.ejogrb.2014.0 6.030 Epub 2014 Jul 7. PubMed PMID: 25079491.

11. Giambattista E, Ossola MW, Duiella SF, Crovetto F, Acaia B, Somigliana E, Fedele L. Predicting factors for emergency peripartum hysterectomy in women with placenta previa. Arch Gynecol Obstet. 2012 Apr;285(4):901-6. http://dx.doi.org/10.1007/s00404-0112074-8 Epub 2011 Sep 7. PubMed PMID: 21898078. 
12. Yaegashi N, Chiba-Sekii A, Okamura K. Emergency postpartum hysterectomy in women with placenta previa and prior cesarean section. Int J Gynaecol Obstet. $2000 \quad$ Jan;68(1):49-52. http://dx.doi.org/10.1016/S00207292(99)00184-8 PubMed PMID: 10687838 .

13. Miller DA, Chollet JA, Goodwin TM. Clinical risk factors for placenta previaplacenta accreta. Am J Obstet Gynecol. 1997 Jul;177(1):210-4. http://dx.doi.org/10.1016/S00029378(97)70463-0 PubMed PMID: 9240608.

14. Wu S, Kocherginsky M, Hibbard JU. Abnormal placentation: twenty-year analysis. Am J Obstet Gynecol. 2005 May;192(5):1458-61.

http://dx.doi.org/10.1016/j.ajog.2004.12. 074 PubMed PMID: 15902137.

15. Clark SL, Yeh SY, Phelan JP, Bruce S, Paul RH. Emergency hysterectomy for obstetric hemorrhage. Obstet Gynecol. 1984 Sep;64(3):376-80. PubMed PMID: 6462567.

16. El-Jallad MF, Zayed F, Al-Rimawi HS. Emergency peripartum hysterectomy in Northern Jordan: indications and obstetric outcome (an 8-year review). Arch Gynecol Obstet. 2004 Dec;270(4):271-3. http://dx.doi.org/10.1007/s00404-0030563-0 Epub 2003 Dec 16. PubMed PMID: 14676963.

17. Karayalçın R, Özcan S, Özyer Ş, Mollamahmutoğlu L, Danışman N. Emergency peripartum hysterectomy. Arch Gynecol Obstet. 2011 Apr;283(4):723-7. http://dx.doi.org/10.1007/s00404-0101451-z Epub 2010 Mar 30. PubMed PMID: 20352237.
18. Çetin $O$, Şen $C$, Çetin ID, Uludağ $S$, Aydoğan $\mathrm{B}$, Erenel $\mathrm{H}$. [Evaluation of the emergency peripartum hysterectomy cases: Experience of 5 years.] Perinatal Journal. 2011;19(3):76-80. http://dx.doi.org/10.2399/PRN.11.01920 $\underline{06}$ Turkish

19. Owolabi MS, Blake RE, Mayor MT, Adegbulugbe HA. Incidence and determinants of peripartum hysterectomy in the metropolitan area of the District of Columbia. J Reprod Med. 2013 Mar-Apr;58(3-4):167-72. PubMed PMID: 23539887.

20. Oyelese Y, Smulian JC. Placenta previa, placenta accreta, and vasa previa. Obstet Gynecol. 2006 Apr;107(4):927-41. http://dx.doi.org/10.1097/01.AOG.00002 07559.15715.98 PubMed PMID: 16582134 .

21. Guzman NA, Argani $\mathrm{CH}$. Third trimester bleeding. In: Hurt $\mathrm{KJ}$, Guile $\mathrm{MW}$, Bienstock JL, Fox HE, Wallach EE, editors. The Johns Hopkins Manual of Gynecology and Obstetrics. 4th ed. Philadelphia : Lippincott Williams Wilkins; 2011; p. 130-136.

22. Love CD, Wallace EM. Pregnancies complicated by placenta praevia: what is appropriate management? $\mathrm{Br} \mathrm{J}$ Obstet Gynaecol. 1996 Sep;103(9):864-7. http://dx.doi.org/10.1111/j.14710528.1996.tb09903.x PubMed PMID: 8813304.

23. Committee on Obstetric Practice. Committee opinion no. 529: placenta accreta. Obstet Gynecol. 2012 Jul;120(1):207-11. http://dx.doi.org/10.1097/AOG.0b013e3 18262e340 PubMed PMID: 22914422. 